\title{
EFFECTS OF EXERCISE INTENSITY AND CARDIORESPIRATORY FITNESS ON THE ACUTE RESPONSE OF ARTERIAL STIFFNESS TO EXERCISE IN OLDER ADULTS
}

\author{
MARIA PERISSIOU ${ }^{1}$ \\ TOM G. BAILEY ${ }^{1,2}$ \\ MARK WINDSOR $^{1}$ \\ MiCHAEL NAM $^{3}$ \\ KIM GREAVES ${ }^{1,3}$ \\ ANTHONY S. LEICHT ${ }^{4}$ \\ JONATHAN GOLLEDGE ${ }^{5,6}$ \\ CHRISTOPHER D. ASKEW ${ }^{1}$
}

${ }^{1}$ VasoActive Research Group, School of Health and Sport Sciences, University of the Sunshine Coast, Queensland, Australia.

${ }^{2}$ Centre for Research on Exercise, Physical Activity and Health, School of Human Movement and Nutrition Sciences, The University of Queensland, Brisbane, Queensland, Australia.

${ }^{3}$ Sunshine Coast University Hospital, Sunshine Coast Hospital and Health Service, Australia

${ }^{4}$ Sport and Exercise Science, James Cook University, Townsville, Queensland, Australia.

${ }^{5}$ Queensland Research Centre for Peripheral Vascular Disease, James Cook University, Townsville, Queensland, Australia.

${ }^{6}$ Department of Vascular and Endovascular Surgery, The Townsville Hospital, Townsville, Queensland, Australia.

SHORT TITLE: Exercise intensity and arterial stiffness in older adults

CONFLICT OF INTEREST: None

DISCLAIMERS: None

FIGURES: 3 TABLES: 3

WORD COUNT: 4,473

\section{AUTHOR FOR CORRESPONDENCE:}

*A/Prof Christopher Askew. VasoActive Research Group - School of Health and Sport Sciences, University of the Sunshine Coast, Locked bag 4, Maroochydore DC, Australia. Email: caskew@usc.edu.au ORCID:0000-0001-8076-8789 


\begin{abstract}
Purpose: Increased arterial stiffness is observed with ageing and in individuals with low cardiorespiratory fitness $\left(\dot{V}_{2 \text { peak }}\right)$, and associated with cardiovascular risk. Following an exercise bout, transient arterial stiffness reductions offer short-term benefit, but may depend on exercise intensity. This study assessed the effects of exercise intensity on post-exercise arterial stiffness in older adults with varying fitness levels. Methods: Fifty-one older adults $(72 \pm 5 \mathrm{y})$ were stratified into fitness tertiles $\left(\dot{\underline{V}} \mathrm{O}_{2 \text { peak }}:\right.$ low-, $22.3 \pm 3.1$; mid-, $27.5 \pm 2.4$ and high-fit $\left.36.3 \pm 6.5 \mathrm{~mL} \cdot \mathrm{kg}^{-1} \cdot \mathrm{min}^{-1}\right)$. In a randomised order, participants underwent control (no-exercise), moderate-intensity continuous exercise ( $40 \%$ of peak power output; PPO), and higher-intensity interval exercise ( $70 \%$ of PPO) protocols. Pulse wave velocity (PWV), augmentation index (AIx75) and reflection magnitude (RM) were assessed at rest and during 90 min of recovery following each protocol. Results: After control, delta PWV increased over time $(\mathrm{P}<0.001)$ and delta RM was unchanged. After higher-intensity interval exercise, delta PWV $(\mathrm{P}<0.001)$ and delta $\mathrm{RM}(\mathrm{P}<0.001)$ were lower to control in all fitness groups. After moderate-intensity continuous exercise, delta PWV was not different to control in lowfit adults ( $\mathrm{P}=0.057)$, but was lower in the mid- and higher-fit older adults. Post-exercise AIx75 was higher to control in all fitness groups $(\mathrm{P}=0.001)$. Conclusions: In older adults, $\mathrm{PWV}$ increases during seated rest and this response is attenuated after higher-intensity interval exercise, regardless of fitness level. This attenuation was also observed after moderate-intensity continuous exercise in adults with higher, but not lower fitness levels. Submaximal exercise reveals differences in the arterial stiffness responses between older adults with higher and lower cardiorespiratory fitness.
\end{abstract}

Keywords: pulse wave velocity; wave reflection characteristics; exercise intensity; ageing 


\author{
ABBREVIATIONS \\ AIx75-Augmentation index corrected for heart rate \\ cDBP-Central diastolic blood pressure \\ cPP-Central pulse pressure \\ cSBP- Central systolic blood pressure \\ HR-Heart rate \\ LMM-Linear mixed model \\ MAP-Mean arterial pressure \\ $\mathrm{Pb}$ - Backward pressure wave \\ Pf- Forward pressure wave \\ PPO- Peak power output \\ PWV-Pulse wave velocity \\ RM- Reflection magnitude \\ RPE- Rate of perceived exertion \\ $\dot{V} \mathrm{O}_{2 \text { peak }}$ - Peak oxygen consumption
}




\section{INTRODUCTION}

Age related arterial dysfunction is characterised by thickening of the artery wall (Tsao et al. 2014), a reduction in endothelial and autonomic function (Thijssen et al. 2016), and increased arterial stiffness. Elevated arterial stiffness is one of the earliest detectable manifestations of these adverse structural and functional changes to the vasculature, and contributes to the incidence of hypertension and the development of atherosclerosis (McEniery et al. 2005; Cecelja and Chowienczyk 2012). Carotid to femoral pulse wave velocity (PWV) is the criterion index representing central arterial stiffness (Van Bortel et al. 2012). Stiffening of the peripheral arteries also leads to an early return of the reflected pressure wave contributing to increases in central pulse pressure and arterial wall stress (Nichols et al. 2011). Wave reflection characteristics are represented by the augmentation index (AIx) and reflection magnitude (RM) (Nichols and Singh 2002; Westerhof et al. 2006). Increases in PWV, AIx and RM at rest are independently associated with the future risk of cardiovascular events and mortality (Mitchell et al. 2010; Chirinos et al. 2012); however arterial stiffness is reduced with regular physical activity (Gando et al. 2016) and aerobic-exercise training in older adults (Kim et al. 2016; Fujie et al. 2014; Fujie et al. 2015).

The benefits of regular exercise on vascular structure and function are commonly attributed to the repeated, transient, hemodynamic perturbations observed in response to a single bout of exercise (Romero et al. 2017; Green and Smith 2017). Reductions in arterial stiffness are evident after a single bout of sub-maximal exercise in younger adults (Kingwell et al. 1997; Mutter et al. 2017), and are suggested to provide a window of benefit (Luttrell and Halliwill 2015), including a transient reduction in central blood pressure (Millen et al. 2016). On the other hand, pronounced post-exercise increases in central blood pressure and PWV have been reported in younger adults who are obese (Bunsawat et al. 2017a) or have untreated hypertension (Gkaliagkousi et al. 2014). These increases in central blood pressure and PWV may be indicative of exercise-related risk in adults with established cardiovascular disease risk factors (Goodman et al. 2016).

While higher levels of cardiorespiratory fitness are associated with lower basal (i.e. resting) arterial stiffness in older adults (Gando et al. 2016), the influence of cardiorespiratory fitness on the post- 
exercise arterial stiffness response is not well defined. In younger adults, post-exercise PWV is elevated in those with lower compared to higher cardiorespiratory fitness (Moore et al. 2016). With small increases in cardiorespiratory fitness with training, a transient post-exercise decrease in AIx, but not PWV, was reported in middle-aged post-menopausal females (Akazawa et al. 2015). To date, there have been no comparisons of the post-exercise arterial stiffness response between older adults with lower and higher levels of cardiorespiratory fitness.

Higher-intensity interval exercise is increasingly recommended for older adults and clinical populations as it enables individuals to exercise at an intensity that may not be sustained with continuous exercise (Francois and Little 2015). Acute higher-intensity interval exercise is reported to induce a greater reduction in PWV and AIx compared to a bout of moderate intensity exercise in younger adults (Tordi et al. 2010; Hanssen et al. 2015); however, the short-term responses of arterial stiffness to a single bout of exercise have not yet been clearly established in older adults. A better understanding of these responses, and how they are influenced by exercise intensity and cardiorespiratory fitness, would provide a greater insight into the potential risks and benefits of exercise among older adults. Therefore, this study aimed to compare the effect of moderate-intensity continuous and higher-intensity interval exercise on indices of post-exercise arterial stiffness, including PWV and wave reflection characteristics (AIx, and RM) between older adults with low, mid and higher levels of cardiorespiratory fitness.

\section{METHODS}

\section{Experimental Overview}

Participants underwent four laboratory visits, each following an overnight fast, refraining from alcohol and exercise for $24 \mathrm{~h}$, and caffeine for $12 \mathrm{~h}$, before each visit. Participants were required to consume a standardised meal consisting of oat biscuits (20g carbohydrate, $8 \mathrm{~g}$ fat) $3 \mathrm{~h}$ prior to attending the laboratory. Visit 1 included an incremental maximal cycling test for the determination of cardiorespiratory fitness $\left(\dot{V} \mathrm{O}_{2 \text { peak }}\right)$ and peak power output. Three experimental visits were then conducted in a cross-over, counter-balanced randomised order, and consisted of a no-exercise control, a moderate-intensity continuous and a higher-intensity interval exercise protocol. Arterial stiffness was 
measured at baseline and at multiple time points during $90 \mathrm{~min}$ of supine recovery $(0,20,40,60$ and 90 min). Lab conditions were standardised for each session in a climate controlled room $\left(23 \pm 1{ }^{\circ} \mathrm{C}\right)$. To control for the diurnal variation of blood pressure and arterial stiffness, each individual performed the three visits at the same time of day, separated by 7 days (Li et al. 2014).

\section{Participants}

Fifty-one healthy older males and females aged $71 \pm 5$ y were recruited through local advertisements. Participants were included if they were aged $60-86 \mathrm{y}$, able to complete cycling exercise and were nonsmokers ( $>12$ months no smoking history). Participants were excluded if they had a known chronic metabolic or cardiovascular condition, or uncontrolled hypertension (average $\mathrm{SBP} \geq 140 \mathrm{mmHg}$ and/or an average DBP $\geq 90 \mathrm{mmHg}$ ). Participants were informed of the methods and study design verbally and in writing before providing written informed consent. The study conformed to the Declaration of Helsinki and was approved by the institutional ethics committees.

\section{Maximal incremental cycling test}

This test was performed on an electro-magnetically braked cycle ergometer (Lode Corival, Groningen, Netherlands). Following a 3-min warm up $(0 \mathrm{~W})$, the test began at $20 \mathrm{~W}$ and then increased by $10 \mathrm{~W}$ each minute until participants reached their maximum load. Prior to the test, participants were fully familiarised with the test procedures and instructed to provide a maximum effort during the test. Participants self-selected a pedal cadence ( $>60 \mathrm{rpm}$ ) and maintained this throughout the test. Expired gases were collected continuously and data were averaged every $15 \mathrm{~s}$ (Parvo Medics, UT, USA) for the determination of oxygen consumption $\left(\mathrm{LO}_{2} ; \mathrm{mL} \cdot \mathrm{kg}^{-1} \cdot \mathrm{min}^{-1}\right)$. Peak cardiorespiratory fitness was determined as the highest $15 \mathrm{~s}$ average of $\dot{\mathrm{O}_{2}}$ over the last $60 \mathrm{~s}$ of maximal exercise $\left(\dot{V} \mathrm{O}_{2 \text { peak }}\right)$. Heart rate was measured continuously using a 12-lead ECG (Mortara Inc., WI, USA) and recorded, along with perceived exertion (RPE) using the 0-10 Borg scale (Borg 1998), during the final $10 \mathrm{~s}$ of each stage. Peak power output (PPO) at the cessation of exercise was used to establish the exercise intensity in the subsequent experimental visits. 


\section{Exercise and control protocols}

Following pre-test measurements of blood pressure and arterial stiffness, participants performed 24 min of: i) moderate-intensity continuous cycling at $40 \%$ PPO; or ii) higher-intensity interval cycling consisting of $12 \times 60 \mathrm{~s}$ bouts at $70 \%$ PPO, with each interval separated by $60 \mathrm{~s}$ at $10 \%$ PPO; or iii) noexercise control (seated rest). Heart rate and RPE were recorded every 2 min during each protocol. Brachial blood pressure was measured every 6-min using a manual sphygmomanometer. Immediately following each protocol, participants moved back to the supine position for post-protocol measurements of arterial stiffness.

\section{Arterial stiffness measurements}

Indices of arterial stiffness (PWV, AIx and RM) were measured in the supine position using the SphygmoCor Xcel device (AtCor Medical, West Ryde, NSW, Australia), at baseline (after 15 min of quiet rest), and 0-90 min post-protocol. Participants were asked to remain quiet and still, before and during each measurement. Wave reflection characteristic measurements preceded PWV measurements, and these procedures are described in detail below.

Wave reflection characteristics: Brachial artery waveforms were recorded from the right upper arm using the SphygmoCor Xcel (AtCor Medical, Sydney, Australia) and following standard guidelines (Hwang et al. 2014). Following triplicate assessment of blood pressure, a corresponding aortic pressure waveform was generated by applying a proprietary digital signal processing and transfer function (Butlin et al. 2012), from which central systolic (cSBP), diastolic (cDBP), central pulse pressure (cPP), mean arterial pressure (MAP), augmentation pressure (AP), and AIx, were derived. Central pulse pressure is calculated as the difference between cSBP and cDBP. Augmentation pressure is defined as the difference between cSBP and the pressure at the inflection point (the merging of forward and reflected waves). AIx is defined as the augmentation pressure expressed as a percentage of pulse pressure. As AIx is significantly affected by heart rate (Wilkinson et al. 2000), the index was corrected for a heart rate at 75 beats per minute (AIx75). Wave separation analysis was performed using SphygmoCor CVMS software (v.9). This method assumes a triangular-shaped flow wave approximated 
from the estimated aortic pressure wave (Westerhof et al. 2006). The forward (Pf) and reflected $(\mathrm{Pb})$ pressure waves correspond to the peak and the end of the assumed flow wave, respectively. The reflection magnitude $(\mathrm{RM})$ is calculated as the ratio of the $\mathrm{Pb}$ to the $\mathrm{Pf}(\mathrm{RM}=\mathrm{Pb} / \mathrm{Pf} * 100)$.

Pulse wave velocity $(P W V)$ : To assess carotid-femoral PWV, pulse waveforms were recorded simultaneously from the right carotid artery using a hand-held high fidelity applanation tonometer, and the right femoral artery using a cuff placed at mid-thigh level. The exact placement of the cuff over the thigh and of the tonometer on the carotid artery was marked with an indelible waterproof skin marker and the distance between the carotid site and the femoral artery was measured and replicated for all repeated sessions. The distance from the inguinal fold to the femoral cuff was standardised at $200 \mathrm{~mm}$. After a stable carotid pulse signal was detected, the thigh cuff was inflated to $80 \mathrm{mmHg}$ to obtain a concurrent femoral pulse waveform. Measurements were based on $10 \mathrm{~s}$ pulse wave traces that were free of artefact and met the quality control threshold of the SphygmoCor Xcel device for pulse-to-pulse variability. PWV was then determined by calculating the ratio of the distance between the carotid and femoral arteries to the transit time; measured as the time delay between the arrival of the pulse wave at the common carotid artery and the common femoral artery (Wilkinson et al. 2010). The coefficient of variation for resting PWV between visits in this study was $6.9 \%$, which is consistent with previous reports (Millasseau et al. 2005).

\section{Statistical analyses}

Based on previous literature (Doonan et al. 2013) who reported a post-exercise difference of the change in PWV of $1.2 \pm 2.0 \mathrm{~m} \cdot \mathrm{s}^{-1}$ between males and females, our power calculation revealed that a cohort of 17 participants per group (assuming a between group post-exercise difference in PWV of $1.2 \mathrm{~m} . \mathrm{s}^{-1}$ with a SD of $2 \mathrm{~m} \cdot \mathrm{s}^{-1}$ and $>80 \%$ power) would be required to reveal significant difference in the post-exercise PWV response between fitness groups. To differentiate the cohort on the basis of cardiorespiratory fitness, participants were stratified into tertiles based on their $\dot{V} \mathrm{O}_{2 \text { peak. }}$ A Linear Mixed Model (LMM) was used to compare anthropometric characteristics and a Pearson's chi squared test was used to compare categorical data between the three fitness groups. A two-way (group*protocol) LMM was used 
to compare baseline arterial stiffness indices [PWV $\left(\mathrm{m}^{\mathrm{s}} \mathrm{s}^{-1}\right)$, AIx75 (\%) and RM (\%)] across the study visits. A three-way (group*protocol*time) LMM was used to compare measurements of arterial stiffness indices and central blood pressure among fitness groups (low-, mid- and high-fit group), across "time" (baseline, 0-, 20-, 40-, 60-, and 90-min post) and between each protocol (control, moderate- and higher-intensity exercise). Data were also analysed as changes from baseline (delta) to account for any baseline variance. Three-way LMM analysis was also used to detect any differences in heart rate, blood pressure and perceived exertion in response to the protocols among the fitness groups, across time (at 2 min intervals for HR and RPE, and at 6 min intervals for BP) during each protocol. Statistically significant interactions were further investigated with multiple comparisons using the least significant difference approach (Rothman 1990). Analyses were conducted using the Statistical Package for Social Sciences (Version 22; IBM SPSS Inc., Chicago, IL). Statistical significance was set at $\mathrm{P}<0.05$ and exact $\mathrm{P}$ values are cited ( $\mathrm{P}$ values of 0.000 are reported as $<0.001$ ). Data are presented in the text as mean and $95 \%$ confidence interval $(95 \% \mathrm{CI})$ unless otherwise stated.

\section{RESULTS}

\section{Participant characteristics}

Participant characteristics of the complete cohort, and comparisons between the low, mid and high fitness groups, are shown in Table 1. Cardiorespiratory fitness, measured as $\dot{V}_{2 p a a k}$, was higher in the high-fit group compared to mid-fit $(\mathrm{P}<0.001)$ and lower-fit groups $(\mathrm{P}<0.001)$ (Table 1$)$.

\section{Heart rate, mean arterial pressure and perceived exertion during the experimental protocols}

Mean power output (W) during exercise was greater in the higher-fit group [moderate-intensity continuous: mean $=80 \mathrm{~W},(95 \% \mathrm{CI}, 71$ to 91$)$; higher-intensity intervals: mean $=140 \mathrm{~W}(95 \% \mathrm{CI}, 133$ to 152$)$ ] compared to the mid [moderate-intensity continuous: mean $=64 \mathrm{~W},(95 \% \mathrm{CI}, 48$ to 74$)$; higherintensity intervals: mean $=112 \mathrm{~W}(95 \% \mathrm{CI}, 91$ to 123$), \mathrm{P}<0.001$ ] and low-fit group [moderate-intensity continuous: mean $=52 \mathrm{~W},(95 \% \mathrm{CI}, 45$ to 64$)$; higher-intensity intervals: mean $=91 \mathrm{~W}(95 \% \mathrm{CI}, 82$ to 103), $\mathrm{P}<0.001]$. No differences were observed among the three fitness groups during exercise for mean heart rate $(\mathrm{P}=0.12)$, mean arterial pressure $(\mathrm{P}=0.94)$ and $\mathrm{RPE}(\mathrm{P}=0.29)$. Mean heart rate was greater 
during higher-intensity interval exercise [mean heart rate $109 \mathrm{~b} \cdot \min ^{-1}(95 \% \mathrm{CI}, 98$ to 115$)$ ] compared to moderate-intensity continuous exercise [mean heart $91 \mathrm{~b} \cdot \mathrm{min}^{-1}(95 \% \mathrm{CI}, 78$ to $100, \mathrm{P}<0.001)$ ], and was higher during both exercise protocols compared to control $(\mathrm{P}<0.05)$. MAP was greater during higher-intensity interval [mean MAP $108 \mathrm{mmHg}$ (95\% CI, 98 to 112)] compared to moderate-intensity continuous exercise [mean MAP $103 \mathrm{mmHg}$ (95\% CI, 89 to 106), $\mathrm{P}=0.002$ ] and was also higher during both exercise protocols than during control $(\mathrm{P}<0.05)$. Mean RPE was 4 (95\% CI, 3 to 4$)$ during higherintensity interval exercise compared to $3(95 \% \mathrm{CI}, 2$ to $3, \mathrm{P}<0.001)$ during moderate-intensity continuous exercise.

\section{Arterial stiffness and central blood pressure indices at baseline and in response to exercise}

Arterial stiffness and central blood pressure indices at baseline and during recovery ( 0 to $90 \mathrm{~min}$ post) after exercise/control protocols for the three fitness groups (low-, mid-, and high-fit) are shown in Tables 2 and 3. The relative change (delta) from baseline in PWV, AIx75 and RM among the three fitness groups for each protocol are shown in Fig 1-3. Findings are summarised below.

Arterial stiffness indices at baseline were similar across the three separate testing days (preexercise/control). AIx75 at baseline was $9.4 \%$ (95\%CI 2.3 to $16, \mathrm{P}=0.010)$ higher in the lower-fit compared to the higher-fit group (Table 2). There were no differences in PWV and RM between fitness groups.

We did not observe a three-way (protocol*group*time) interaction for any of the arterial stiffness and central blood pressure indices (Tables 2 and 3). In control, PWV increased from baseline at all timepoints, whereas after the exercise protocols PWV increased from baseline at 90 min only (Table 2). A group*protocol interaction $(\mathrm{P}<0.001)$ revealed that delta PWV was lower after both exercise protocols in the mid- and high-fit groups, compared with delta PWV in control (Fig 1). Delta PWV was lower after higher-intensity interval exercise compared to moderate-intensity continuous exercise in the midand low-fit groups (Fig $1 \mathrm{~b}$ and c). Conversely, delta PWV was similar after moderate-intensity continuous exercise compared to control in the low-fit group, but was significantly lower after higherintensity interval exercise compared to control (Fig 1). 
AIx 75 decreased and remained below baseline for 90 min after control; and AIx 75 was also significantly lower than baseline 40 to 90 min after both exercise protocols (Table 2). Delta AIx75 was significantly lower after control compared to both exercise protocols in all fitness groups (Fig 2). RM was unchanged after the control protocol, and decreased to below baseline levels for 20 min after moderate-intensity continuous exercise and for 90 min after higher-intensity interval exercise in all fitness groups (Table 2). A protocol effect $(\mathrm{P}<0.001)$ revealed that delta $\mathrm{RM}$ was significantly lower after both exercise protocols compared with control, in all the fitness groups (Fig 3). Further, a group*protocol interaction $(\mathrm{P}=0.009)$ revealed that delta $\mathrm{RM}$ was lower after higher-intensity interval exercise compared to moderate-intensity continuous exercise in the mid- and low-fit groups, but not in the high-fit group (Fig $3 \mathrm{~b}$ and $\mathrm{c})$.

After control, heart rate decreased below baseline for 90 min in all fitness groups. After both exercise protocols heart rate increased above baseline levels in all fitness groups, before returning to baseline by 60 min post (Table 3). In all fitness groups, cSBP, cDBP and cPP increased above baseline for $90 \mathrm{~min}$ after control. After both exercise protocols in all fitness groups, cPP increased immediately after exercise ( 0 min post), and decreased to below baseline levels for up to $60 \mathrm{~min}$ post-exercise (Table 3 ).

\section{DISCUSSION}

This study demonstrates that the post-exercise arterial stiffness response is dependent on both the intensity of exercise and the level of cardiorespiratory fitness in healthy older adults. We observed significant increases in PWV following seated rest (control), with negligible changes in RM. Following higher-intensity interval exercise, PWV and RM were lower compared to control in older adults of all fitness levels. Following moderate-intensity continuous exercise, this relative attenuation in PWV compared to control was also achieved in the mid- and higher-fit older adults, but not in older adults with low cardiorespiratory fitness.

\section{Arterial stiffness at rest}

It has previously been suggested that high levels of cardiorespiratory fitness suppress the age-related increases in resting arterial stiffness (Gando et al. 2016). In the current cohort of older adults, we found 
that resting AIx 75 was lowest in those with the highest cardiorespiratory fitness, which is consistent with previous reports (Ramos et al. 2016; Binder et al. 2006; Denham et al. 2016). In contrast, we did not observe differences in the resting measures of PWV between the fitness groups. There are limited studies of the effect of fitness on PWV in older adults, showing that PWV is lower in masters athletes (Vaitkevicius et al. 1993) and high-fit post-menopausal females (Gando et al. 2010) when compared to low-fit control groups. In a group of middle-aged adults, with and without the metabolic syndrome, Jae et al. (2010) reported that increases in fitness were associated with reductions in the brachial-to-ankle PWV (Jae et al. 2010). This fitness effect was not seen in a similar cohort when PWV was assessed at the carotid-to-femoral segment (Ramos et al. 2016), which is consistent with our finding in older adults.

The conflicting effects of fitness on resting measures of AIx75 and PWV highlights important differences between the determinants of these indices of arterial stiffness. There is a progressive stiffening of the arterial tree from the ascending aorta and large elastic arteries towards the peripheral muscular conduit arteries (London and Pannier 2010). Carotid-to-femoral PWV quantifies the velocity of the pulse wave through the aorta, which undergoes the greatest stiffening with age (Mitchell et al. 2004). Augmentation index (AIx75) characterizes the magnitude of the reflected pressure wave as it contributes to systolic blood pressure, and has therefore been reported to reflect peripheral arterial stiffness (Nichols 2005). Recent studies have challenged this view, suggesting that augmentation index is largely determined by aortic reservoir pressure (Wang et al. 2003). Aortic reservoir pressure increases with age, probably as a result of impaired aortic compliance and the limited ability to buffer increases in aortic blood volume during cardiac ejection (Davies et al. 2010). Aortic reservoir pressure has recently been shown to be lower in middle-aged adults with higher cardiorespiratory fitness (Ramos et al. 2016), and therefore may contribute to the lower AIx 75 of the higher-fit older adults in the present study. Reflected pressure from the peripheral arteries is reported to be better represented by the reflection magnitude (RM, ratio of forward to backward pressure waves) (Hughes et al. 2013; Millen et al. 2016). Our finding that RM did not differ between the fitness groups further supports the interpretation that differences in resting AIx75 between fitness groups are not likely to be caused by alterations in peripheral reflected wave function. 


\section{Post-exercise arterial stiffness}

During recovery from a bout of aerobic exercise, indices of arterial stiffness have been reported to increase (Gkaliagkousi et al. 2014; Hull et al. 2011), decrease (Lane et al. 2013; Heffernan et al. 2007a; Kingwell et al. 1997), or remain unchanged (McClean et al. 2011; Akazawa et al. 2015) compared with baseline levels. This variance in the post-exercise arterial stiffness response is suggested to be due to the anatomical segment being assessed, the frequency of measures, as well as the age and health status of study participants (Mutter et al. 2017). In the current cohort of healthy older adults, we observed decreases in wave reflection characteristics following exercise, but negligible changes in carotidfemoral PWV. Carotid-femoral PWV has been shown to be less susceptible to acute post-exercise changes compared with peripheral PWV, i.e. changes in femoral-dorsalis pedis PWV (Heffernan et al. 2007b; Munir et al. 2008). The RM is reported to represent the reflected pressure from the peripheral arteries (Hughes et al. 2013; Millen et al. 2016), which is dependent on changes in downstream arterial function, including any changes as a result of local muscle activity (Hickson et al. 2016). Hence, it is likely that the reductions in wave reflection observed in the present study relate to peripheral vasodilation in the lower limbs during the period immediately following exercise.

We included a no-exercise control condition, which is a strength of the study design and allowed us to control for the influence of time and supine rest on changes in arterial stiffness. Indeed, we observed a progressive rise in PWV, which may reflect an increase in vascular tone (Fok et al. 2012), and a reduction in AIx75, which may be due to a redistribution of blood volume and an altered cardiac-preload (van de Velde et al. 2017) during the supine control condition. Compared to control, post-exercise PWV and RM were lower following a bout of higher-intensity interval exercise, while post-exercise AIx75 was higher compared with control. These findings challenge previous studies that did not use a timeadjusted control comparison and reported post-exercise reductions in AIx75 (Hanssen et al. 2015; Lane et al. 2013; Radhakrishnan et al. 2016; Millen et al. 2016). Our finding of a higher AIx75 after exercise compared to after a period of rest further supports the notion that the augmentation index is largely determined by aortic reservoir pressure, as discussed earlier, which increases with exercise (Climie et al. 2015). McClean et al. (2011) previously observed no differences in post-exercise PWV compared 
to control in younger adults, however the authors only measured PWV immediately following exercise (McClean et al. 2011). Similar to our findings, Wang et al. (2014) reported a lower arterial stiffness (cardio-ankle vascular index; CAVI) after both continuous and interval moderate-intensity exercise compared to control when measured during 40 min of recovery (Wang et al. 2014), although this study also observed a decrease in arterial stiffness from baseline after exercise. This is the first study in healthy older adults to report a lower post-exercise arterial stiffness, where the response is attenuated compared with control, (PWV and RM) following a bout of higher-intensity exercise.

Compared with higher-intensity interval exercise, the response of post-exercise PWV and RM to moderate intensity continuous exercise was less pronounced in both the low and mid-fit groups. This is consistent with the augmented effect of higher-intensity compared to moderate-intensity exercise on lowering post-exercise arterial stiffness in some (Tordi et al. 2010; Hanssen et al. 2015) but not all studies (Siasos et al. 2016) in younger adults. Intensity-dependent changes in post-exercise arterial stiffness are complex, and may be due to increases in vessel tone and reductions in central pressure following higher intensity exercise (Millen et al. 2016). We observed transient reductions in cPP following exercise in this study, and whilst this has previously been associated with corresponding changes in PWV (Lim et al. 2016), we did not observe an intensity (protocol) effect for cPP and thus it is unlikely to explain our findings. Blood flow and shear stress are augmented with increased exercise intensity (Santana et al. 2013; Bond et al. 2015) and may partly explain the intensity effect observed in post-exercise PWV and RM. Shear-mediated increases in endothelial function (Munir et al. 2008) and the activation of vasodilators e.g. nitric-oxide and prostaglandins (Poveda et al. 1998), and inhibition of vasoconstrictors e.g. endothelin-1 expression (Di Francescomarino et al. 2009) have all been associated with a transient lowering of arterial stiffness after exercise. Further, exercise-induced suppression of pro-inflammatory cytokines (Jablonski et al. 2015) and intensity-dependant decreases in post-exercise sympathetic nerve activity (Heffernan et al. 2007a) may also contribute to a lower arterial stiffness following higher-intensity exercise.

Post-exercise arterial stiffness has previously been reported to be lower in younger adults with high, compared with low, levels of cardiorespiratory fitness (Moore et al. 2016). A similar trend was observed 
in the current study following moderate-intensity exercise, where the response of the low-fit group (delta PWV) did not differ to the rises observed during control, whereas participants in the high-fit group demonstrated an attenuation of the PWV response after both exercise intensities compared to control. This suggests that higher levels of cardiorespiratory fitness may improve the sensitivity or responsiveness of the vasculature to submaximal exercise in older adults, and this may relate to the improved endothelial function and vascular tone seen with training and increased fitness in older adults (DeSouza et al. 2000; Pialoux et al. 2009). It is also possible that the absolute exercise intensity, which was greatest in the high-fit group, may have a generated a greater stimulus for post-exercise changes in arterial stiffness and contributed to our observations. However, it is important to note that there were no differences in heart rate, blood pressure or perceived exertion between the groups during exercise.

We found significant differences in post-exercise PWV and RM between the fitness groups, despite there being no difference in the resting measures. These findings support the recent suggestion that subtle underlying differences in arterial stiffness that are undetectable at rest become more pronounced with acute exercise, (Keith et al. 2013; Schultz et al. 2017). It has also been reported that the arterial stiffness response to maximal exercise may be a useful tool for detecting small, but clinically relevant changes in vascular health (Bunsawat et al. 2017b; Shim et al. 2011) and we also now show that submaximal exercise may reveal important differences in arterial stiffness between adults with higher and lower levels of cardiorespiratory fitness.

As increased PWV and RM during seated rest may reflect increased cardiovascular risk (Mitchell et al. 2010; Chirinos et al. 2012), and the attenuation of arterial stiffness with exercise may reflect a transient cardiovascular benefit, or a reduction in risk (Millen et al. 2016). Similar to the relationship between acute and chronic blood pressure responses to exercise, (Kiviniemi et al. 2014), the lowering of arterial stiffness may be additive and contribute to the longer term reductions in resting arterial stiffness after exercise training in older adults (Kim et al. 2016). Whether the acute influence of exercise intensity or cardiorespiratory fitness seen in the present study has any implications for the effect of exercise training on arterial stiffness in older adults remains to be determined. 


\section{Limitations}

This study included healthy older male and female adults, and we acknowledge that sex-related differences in arterial stiffness (Coutinho et al. 2013) may limit some comparisons. However, it should be noted that the proportion of males and females was similar in each fitness group in this study, and thus is unlikely to have influenced our findings. The inclusion of participants with controlled hypertension ( $\mathrm{n}=16$ ) may have also influenced our findings, but again the proportion of those with hypertension was similar between groups (30-35\%). Anti-hypertensive medication has been reported to lower PWV at rest (Mahmud and Feely 2008), and may have confounded the differences in arterial stiffness across fitness groups in this study. Finally, we did not include measures of potential mechanisms involved in the changes in arterial stiffness with exercise, and this should be the focus of future research.

\section{Conclusions}

In conclusion, the present study suggests that the post-exercise arterial stiffness response is dependent on both the intensity of exercise and the level of cardiorespiratory fitness in healthy older adults. PWV increases during prolonged seated rest in older adults. Moderate-intensity continuous exercise has a positive attenuation on PWV compared with seated-rest control in those with higher, but not lower, levels of fitness. PWV and RM are lower after higher-intensity interval exercise compared with control in older adults of all levels of cardiorespiratory fitness. Submaximal exercise reveals differences in arterial stiffness responses between adults with higher and lower levels of cardiorespiratory fitness.

\section{Conflict of interest}

The authors declare that they have no conflict of interest.

\section{Acknowledgements}

This research was funded by grants from the National Health and Medical Research Council (1000967, 1022752, 1079369) and The Townsville Hospital. Professor Jonathan Golledge's work is supported by fellowships from the NHMRC (1117061) and the Queensland Government (Senior Clinical Research 
Fellowship). Support for this work was also provided through the Inflammation and Healing Research Cluster at the University of the Sunshine Coast. 


\section{REFERENCES}

Akazawa N, Ra S-G, Sugawara J, Maeda S (2015) Influence of aerobic exercise training on postexercise responses of aortic pulse pressure and augmentation pressure in postmenopausal women. Frontiers in Physiology 6:268. doi:10.3389/fphys.2015.00268

Binder J, Bailey KR, Seward JB, Squires RW, Kunihiro T, Hensrud DD, Kullo IJ (2006) Aortic augmentation index is inversely associated with cardiorespiratory fitness in men without known coronary heart disease. Am J Hypertens 19 (10):1019-1024. doi:10.1016/j.amjhyper.2006.02.012

Bond B, Hind S, Williams CA, Barker AR (2015) The Acute Effect of Exercise Intensity on Vascular Function in Adolescents. Med Sci Sports Exerc 47 (12):2628-2635. doi:10.1249/mss.0000000000000715

Borg G (1998) Borg's Perceived Exertion and Pain Scales. Human Kinetics,

Bunsawat K, Ranadive SM, Lane-Cordova AD, Yan H, Kappus RM, Fernhall B, Baynard T (2017b) The effect of acute maximal exercise on postexercise hemodynamics and central arterial stiffness in obese and normal-weight individuals. Physiological Reports 5 (7):e13226. doi:10.14814/phy2.13226

Butlin M, Qasem A, Avolio AP (2012) Estimation of central aortic pressure waveform features derived from the brachial cuff volume displacement waveform. Conference proceedings : Annual International Conference of the IEEE Engineering in Medicine and Biology Society IEEE Engineering in Medicine and Biology Society Annual Conference 2012:2591-2594. doi:10.1109/embc.2012.6346494

Cecelja M, Chowienczyk P (2012) Role of arterial stiffness in cardiovascular disease. JRSM Cardiovascular Disease 1 (4):cvd.2012.012016. doi:10.1258/cvd.2012.012016

Chirinos JA, Kips JG, Jacobs DR, Jr., Brumback L, Duprez DA, Kronmal R, Bluemke DA, Townsend RR, Vermeersch S, Segers P (2012) Arterial wave reflections and incident cardiovascular events and heart failure: MESA (Multiethnic Study of Atherosclerosis). J Am Coll Cardiol 60 (21):2170-2177. doi:10.1016/j.jacc.2012.07.054

Climie RED, Srikanth V, Keith LJ, Davies JE, Sharman JE (2015) Exercise excess pressure and exercise-induced albuminuria in patients with type 2 diabetes mellitus. American Journal of Physiology - Heart and Circulatory Physiology 308 (9):H1136-H1142. doi:10.1152/ajpheart.00739.2014

Coutinho T, Borlaug BA, Pellikka PA, Turner ST, Kullo IJ (2013) Sex differences in arterial stiffness and ventricular-arterial interactions. J Am Coll Cardiol 61 (1):96-103. doi:10.1016/j.jacc.2012.08.997

Davies JE, Baksi J, Francis DP, Hadjiloizou N, Whinnett ZI, Manisty CH, Aguado-Sierra J, Foale RA, Malik IS, Tyberg JV, Parker KH, Mayet J, Hughes AD (2010) The arterial reservoir pressure increases with aging and is the major determinant of the aortic augmentation index. American journal of physiology Heart and circulatory physiology 298 (2):H580-586. doi:10.1152/ajpheart.00875.2009

Denham J, Brown NJ, Tomaszewski M, Williams B, O’Brien BJ, Charchar FJ (2016) Aortic augmentation index in endurance athletes: a role for cardiorespiratory fitness. European journal of applied physiology 116 (8):1537-1544. doi:10.1007/s00421-016-3407-x

DeSouza CA, Shapiro LF, Clevenger CM, Dinenno FA, Monahan KD, Tanaka H, Seals DR (2000) Regular aerobic exercise prevents and restores age-related declines in endothelium-dependent vasodilation in healthy men. Circulation 102 (12):1351-1357 
Di Francescomarino S, Sciartilli A, Di Valerio V, Di Baldassarre A, Gallina S (2009) The effect of physical exercise on endothelial function. Sports medicine (Auckland, NZ) 39 (10):797-812. doi:10.2165/11317750-000000000-00000

Doonan RJ, Mutter A, Egiziano G, Gomez YH, Daskalopoulou SS (2013) Differences in arterial stiffness at rest and after acute exercise between young men and women. Hypertension Research 36 (3):226-231

Fok H, Jiang B, Clapp B, Chowienczyk P (2012) Regulation of Vascular Tone and Pulse Wave Velocity in Human Muscular Conduit Arteries. Selective Effects of Nitric Oxide Donors to Dilate Muscular Arteries Relative to Resistance Vessels 60 (5):1220-1225. doi:10.1161/hypertensionaha.112.198788

Francois ME, Little JP (2015) Effectiveness and Safety of High-Intensity Interval Training in Patients With Type 2 Diabetes. Diabetes Spectrum : A Publication of the American Diabetes Association 28 (1):39-44. doi:10.2337/diaspect.28.1.39

Fujie S, Hasegawa N, Sato K, Fujita S, Sanada K, Hamaoka T, Iemitsu M (2015) Aerobic exercise training-induced changes in serum adropin level are associated with reduced arterial stiffness in middle-aged and older adults. American Journal of Physiology - Heart and Circulatory Physiology 309 (10):H1642-H1647. doi:10.1152/ajpheart.00338.2015

Fujie S, Sato K, Miyamoto-Mikami E, Hasegawa N, Fujita S, Sanada K, Hamaoka T, Iemitsu M (2014) Reduction of arterial stiffness by exercise training is associated with increasing plasma apelin level in middle-aged and older adults. PLoS ONE 9 (4). doi:10.1371/journal.pone.0093545

Gando Y, Kawano H, Yamamoto K, Sanada K, Tanimoto M, Oh T, Ohmori Y, Miyatani M, Usui C, Takahashi E, Tabata I, Higuchi M, Miyachi M (2010) Age and cardiorespiratory fitness are associated with arterial stiffening and left ventricular remodelling. J Hum Hypertens 24 (3):197-206. doi:10.1038/jhh.2009.57

Gando Y, Murakami H, Kawakami R, Yamamoto K, Kawano H, Tanaka N, Sawada SS, Miyatake N, Miyachi M (2016) Cardiorespiratory Fitness Suppresses Age-Related Arterial Stiffening in Healthy Adults: A 2-Year Longitudinal Observational Study. Journal of Clinical Hypertension 18 (4):292-298. doi:10.1111/jch.12753

Gkaliagkousi E, Gavriilaki E, Nikolaidou B, Triantafyllou G, Douma S (2014) Exercise-Induced Pulse Wave Velocity Changes in Untreated Patients With Essential Hypertension: The Effect of an Angiotensin Receptor Antagonist. The Journal of Clinical Hypertension 16 (7):482-487. doi:10.1111/jch.12340

Goodman JM, Burr JF, Banks L, Thomas SG (2016) The Acute Risks of Exercise in Apparently Healthy Adults and Relevance for Prevention of Cardiovascular Events. The Canadian journal of cardiology 32 (4):523-532. doi:10.1016/j.cjca.2016.01.019

Green DJ, Smith KJ (2017) Effects of Exercise on Vascular Function, Structure, and Health in Humans. Cold Spring Harbor perspectives in medicine. doi:10.1101/cshperspect.a029819

Hanssen H, Nussbaumer M, Moor C, Cordes M, Schindler C, Schmidt-Trucksäss A (2015) Acute effects of interval versus continuous endurance training on pulse wave reflection in healthy young men. Atherosclerosis 238 (2):399-406. doi:http://dx.doi.org/10.1016/j.atherosclerosis.2014.12.038

Heffernan KS, Collier SR, Kelly EE, Jae SY, Fernhall B (2007a) Arterial stiffness and baroreflex sensitivity following bouts of aerobic and resistance exercise. International Journal of Sports Medicine 28 (3):197-203. doi:10.1055/s-2006-924290

Heffernan KS, Jae SY, Echols GH, Lepine NR, Fernhall B (2007b) Arterial stiffness and wave reflection following exercise in resistance-trained men. Med Sci Sports Exerc 39 (5):842-848. doi:10.1249/mss.0b013e318031b03c 
Hickson SS, Nichols WW, Yasmin, McDonnell BJ, Cockcroft JR, Wilkinson IB, McEniery CM (2016) Influence of the central-to-peripheral arterial stiffness gradient on the timing and amplitude of wave reflections. Hypertens Res 39 (10):723-729. doi:10.1038/hr.2016.64

Hughes AD, Park C, Davies J, Francis D, Mc GTSA, Mayet J, Parker KH (2013) Limitations of augmentation index in the assessment of wave reflection in normotensive healthy individuals. PLoS One 8 (3):e59371. doi:10.1371/journal.pone.0059371

Hull JH, Ansley L, Bolton CE, Sharman JE, Knight RK, Cockcroft JR, Shale DJ, Garrod R (2011) The effect of exercise on large artery haemodynamics in cystic fibrosis. Journal of cystic fibrosis : official journal of the European Cystic Fibrosis Society 10 (2):121-127. doi:10.1016/j.jcf.2010.12.001

Hwang MH, Yoo JK, Kim HK, Hwang CL, Mackay K, Hemstreet O, Nichols WW, Christou DD (2014) Validity and reliability of aortic pulse wave velocity and augmentation index determined by the new cuff-based SphygmoCor Xcel. J Hum Hypertens 28 (8):475-481. doi:10.1038/jhh.2013.144

Jablonski KL, Donato AJ, Fleenor BS, Nowlan MJ, Walker AE, Kaplon RE, Ballak DB, Seals DR (2015) Reduced large elastic artery stiffness with regular aerobic exercise in middle-aged and older adults: potential role of suppressed nuclear factor kappa B signalling. J Hypertens. doi:10.1097/hjh.0000000000000742

Jae SY, Heffernan KS, Fernhall B, Oh YS, Park WH, Lee M-K, Choi Y-H (2010) Association between cardiorespiratory fitness and arterial stiffness in men with the metabolic syndrome. Diabetes research and clinical practice 90 (3):326-332. doi:10.1016/j.diabres.2010.08.025

Keith LJ, Rattigan S, Keske MA, Jose M, Sharman JE (2013) Exercise aortic stiffness: Reproducibility and relation to end-organ damage in men. Journal of Human Hypertension 27 (8):516-522

Kim H-K, Hwang C-L, Yoo J-K, Hwang M-H, Lim J, Handberg EM, Nichols WW, Christou DD (2016) All-Extremity Aerobic Exercise Training Improves Carotid Artery Compliance in Older Adults. The FASEB Journal 30 (1 Supplement):lb604

Kingwell BA, Berry KL, Cameron JD, Jennings CL, Dart AM (1997) Arterial compliance increases after moderate-intensity cycling. American Journal of Physiology - Heart and Circulatory Physiology 273 (5 42-5):H2186-H2191

Kiviniemi AM, Hautala AJ, Karjalainen JJ, Piira OP, Lepojarvi S, Ukkola O, Huikuri HV, Tulppo MP (2014) Acute post-exercise change in blood pressure and exercise training response in patients with coronary artery disease. Front Physiol 5:526. doi:10.3389/fphys.2014.00526

Lane AD, Ranadive SM, Yan H, Kappus RM, Cook MD, Sun P, Woods JA, Wilund K, Fernhall B (2013) Effect of sex on wasted left ventricular effort following maximal exercise. Int J Sports Med 34 (9):770-776. doi:10.1055/s-0032-1329990

Li Y, Cordes M, Recio-Rodriguez JI, Garcia-Ortiz L, Hanssen H, Schmidt-Trucksass A (2014) Diurnal variation of arterial stiffness in healthy individuals of different ages and patients with heart disease. Scandinavian journal of clinical and laboratory investigation 74 (2):155-162. doi:10.3109/00365513.2013.864787

Lim J, Pearman ME, Park W, Alkatan M, Machin DR, Tanaka H (2016) Impact of blood pressure perturbations on arterial stiffness. American Journal of Physiology - Regulatory Integrative and Comparative Physiology 309 (12):R1540-R1545. doi:10.1152/ajpregu.00368.2015

London GM, Pannier B (2010) Arterial functions: how to interpret the complex physiology. Nephrology Dialysis Transplantation. doi:10.1093/ndt/gfq614

Luttrell MJ, Halliwill JR (2015) Recovery from exercise: vulnerable state, window of opportunity, or crystal ball? Frontiers in Physiology 6:204. doi:10.3389/fphys.2015.00204 
Mahmud A, Feely J (2008) $\beta$-Blockers Reduce Aortic Stiffness in Hypertension but Nebivolol, Not Atenolol, Reduces Wave Reflection. American Journal of Hypertension 21 (6):663-667. doi:10.1038/ajh.2008.156

McClean CM, Clegg M, Shafat A, Murphy MH, Trinick T, Duly E, McLaughlin J, Fogarty M, Davison GW (2011) The impact of acute moderate intensity exercise on arterial regional stiffness, lipid peroxidation, and antioxidant status in healthy males. Research in Sports Medicine $19(1): 1-13$

McEniery CM, Yasmin, Hall IR, Qasem A, Wilkinson IB, Cockcroft JR (2005) Normal vascular aging: differential effects on wave reflection and aortic pulse wave velocity: the AngloCardiff Collaborative Trial (ACCT). J Am Coll Cardiol 46 (9):1753-1760. doi:10.1016/j.jacc.2005.07.037

Millasseau SC, Stewart AD, Patel SJ, Redwood SR, Chowienczyk PJ (2005) Evaluation of carotidfemoral pulse wave velocity: influence of timing algorithm and heart rate. Hypertension 45 (2):222-226. doi:10.1161/01.HYP.0000154229.97341.d2

Millen AM, Woodiwiss AJ, Norton GR (2016) Post-exercise effects on aortic wave reflection derived from wave separation analysis in young- to middle-aged pre-hypertensives and hypertensives. European journal of applied physiology. doi:10.1007/s00421-016-3391-1

Mitchell GF, Hwang S-J, Vasan RS, Larson MG, Pencina MJ, Hamburg NM, Vita JA, Levy D, Benjamin EJ (2010) Arterial Stiffness and Cardiovascular Events: The Framingham Heart Study. Circulation 121 (4):505-511. doi:10.1161/circulationaha.109.886655

Mitchell GF, Parise H, Benjamin EJ, Larson MG, Keyes MJ, Vita JA, Vasan RS, Levy D (2004) Changes in arterial stiffness and wave reflection with advancing age in healthy men and women: the Framingham Heart Study. Hypertension 43 (6):1239-1245. doi:10.1161/01.HYP.0000128420.01881.aa

Moore SM, Berrones AJ, Clasey JL, Abel MG, Fleenor BS (2016) Arterial hemodynamics are impaired at rest and following acute exercise in overweight young men. Vascular Medicine (United Kingdom) 21 (6):497-505. doi:10.1177/1358863X16666692

Munir S, Jiang B, Guilcher A, Brett S, Redwood S, Marber M, Chowienczyk P (2008) Exercise reduces arterial pressure augmentation through vasodilation of muscular arteries in humans, vol 294. vol 4. doi:10.1152/ajpheart.01171.2007

Mutter AF, Cooke AB, Saleh O, Gomez YH, Daskalopoulou SS (2017) A systematic review on the effect of acute aerobic exercise on arterial stiffness reveals a differential response in the upper and lower arterial segments. Hypertension Research 40 (2):146-172. doi:10.1038/hr.2016.111

Nichols W, O'Rourke M, Vlachopoulos C (2011) McDonald's Blood Flow in Arteries, Sixth Edition: Theoretical, Experimental and Clinical Principles. CRC Press,

Nichols WW (2005) Clinical measurement of arterial stiffness obtained from noninvasive pressure waveforms. Am J Hypertens 18 (1 Pt 2):3s-10s. doi:10.1016/j.amjhyper.2004.10.009

Nichols WW, Singh BM (2002) Augmentation index as a measure of peripheral vascular disease state. Current opinion in cardiology 17 (5):543-551

Pialoux V, Brown AD, Leigh R, Friedenreich CM, Poulin MJ (2009) Effect of Cardiorespiratory Fitness on Vascular Regulation and Oxidative Stress in Postmenopausal Women. Hypertension 54 (5):1014-1020. doi:10.1161/hypertensionaha.109.138917

Poveda JJ, Berrazueta JR, Ochoteco A, Montalban C, Garcia-Unzueta MT, Fernandez C, Pena N, Amado JA (1998) Age-related responses of vasoactive factors during acute exercise. Hormone and metabolic research $=$ Hormon- und Stoffwechselforschung $=$ Hormones et metabolisme 30 (11):668-672. doi:10.1055/s-2007-978955 
Radhakrishnan J, Swaminathan N, Pereira NM, Henderson K, Brodie DA (2016) Acute changes in arterial stiffness following exercise in people with metabolic syndrome. Diabetes and Metabolic Syndrome: Clinical Research and Reviews. doi:10.1016/j.dsx.2016.08.013

Ramos JS, Ramos MV, Dalleck LC, Borrani F, Walker KB, Fassett RG, Sharman JE, Coombes JS (2016) Fitness Is Independently Associated with Central Hemodynamics in Metabolic Syndrome. Medicine \& Science in Sports \& Exercise Publish Ahead of Print. doi:10.1249/mss.0000000000000916

Romero SA, Minson CT, Halliwill JR (2017) The cardiovascular system after exercise. Journal of applied physiology (Bethesda, Md : 1985) 122 (4):925-932. doi:10.1152/japplphysiol.00802.2016

Rothman KJ (1990) No adjustments are needed for multiple comparisons. Epidemiology (Cambridge, Mass) 1 (1):43-46

Santana HA, Moreira SR, Asano RY, Sales MM, Cordova C, Campbell CS, Espindola FS, Sposito AC, Nobrega OT, Simoes HG (2013) Exercise intensity modulates nitric oxide and blood pressure responses in hypertensive older women. Aging clinical and experimental research 25 (1):43-48. doi:10.1007/s40520-013-0017-x

Schultz M, La Gerche A, Sharman J (2017) Blood Pressure Response to Exercise and Cardiovascular Disease, vol 19. doi:10.1007/s11906-017-0787-1

Shim CY, Yang WI, Park S, Kang MK, Ko YG, Choi D, Jang Y, Chung N, Ha JW (2011) Overweight and its association with aortic pressure wave reflection after exercise. American Journal of Hypertension 24 (10):1136-1142

Siasos G, Athanasiou D, Terzis G, Stasinaki A, Oikonomou E, Tsitkanou S, Kolokytha T, Spengos K, Papavassiliou AG, Tousoulis D (2016) Acute effects of different types of aerobic exercise on endothelial function and arterial stiffness. Eur J Prev Cardiol. doi:10.1177/2047487316647185

Thijssen DH, Carter SE, Green DJ (2016) Arterial structure and function in vascular ageing: are you as old as your arteries? The Journal of physiology 594 (8):2275-2284. doi:10.1113/jp270597

Tordi N, Mourot L, Colin E, Regnard J (2010) Intermittent versus constant aerobic exercise: Effects on arterial stiffness. European journal of applied physiology 108 (4):801-809

Tsao CW, Pencina KM, Massaro JM, Benjamin EJ, Levy D, Vasan RS, Hoffmann U, O’Donnell CJ, Mitchell GF (2014) Cross-Sectional Relations of Arterial Stiffness, Pressure Pulsatility, Wave Reflection, and Arterial Calcification. Arteriosclerosis, thrombosis, and vascular biology. doi:10.1161/atvbaha.114.303916

Vaitkevicius PV, Fleg JL, Engel JH, O'Connor FC, Wright JG, Lakatta LE, Yin FC, Lakatta EG (1993) Effects of age and aerobic capacity on arterial stiffness in healthy adults. Circulation 88 (4 Pt 1):1456-1462

Van Bortel LM, Laurent S, Boutouyrie P, Chowienczyk P, Cruickshank JK, De Backer T, Filipovsky J, Huybrechts S, Mattace-Raso FU, Protogerou AD, Schillaci G, Segers P, Vermeersch S, Weber T (2012) Expert consensus document on the measurement of aortic stiffness in daily practice using carotid-femoral pulse wave velocity. J Hypertens 30 (3):445-448. doi:10.1097/HJH.0b013e32834fa8b0

van de Velde L, Eeftinck Schattenkerk DW, Venema P, Best HJ, van den Bogaard B, Stok WJ, Westerhof BE, van den Born BJH (2017) Myocardial preload alters central pressure augmentation through changes in the forward wave. J Hypertens. doi:10.1097/hjh.0000000000001583

Wang H, Zhang T, Zhu W, Wu H, Yan S (2014) Acute effects of continuous and interval lowintensity exercise on arterial stiffness in healthy young men. European journal of applied physiology 114 (7):1385-1392 
Wang JJ, O'Brien AB, Shrive NG, Parker KH, Tyberg JV (2003) Time-domain representation of ventricular-arterial coupling as a windkessel and wave system. American journal of physiology Heart and circulatory physiology 284 (4):H1358-1368. doi:10.1152/ajpheart.00175.2002

Westerhof BE, Guelen I, Westerhof N, Karemaker JM, Avolio A (2006) Quantification of Wave Reflection in the Human Aorta From Pressure Alone: A Proof of Principle. Hypertension 48 (4):595-601. doi:10.1161/01.hyp.0000238330.08894.17

Wilkinson IB, MacCallum H, Flint L, Cockcroft JR, Newby DE, Webb DJ (2000) The influence of heart rate on augmentation index and central arterial pressure in humans. The Journal of Physiology 525 (Pt 1):263-270. doi:10.1111/j.1469-7793.2000.t01-1-00263.x

Wilkinson IB, McEniery CM, Schillaci G, Boutouyrie P, Segers P, Donald A, Chowienczyk PJ (2010) ARTERY Society guidelines for validation of non-invasive haemodynamic measurement devices: Part 1, arterial pulse wave velocity. Artery Research 4 (2):34-40.

doi:http://dx.doi.org/10.1016/j.artres.2010.03.001 
Tables

Table 1. Participant characteristics

\begin{tabular}{|c|c|c|c|c|c|}
\hline Table 1 & $\begin{array}{l}\text { All } \\
(n=51)\end{array}$ & $\begin{array}{l}\text { Low fit } \\
(n=17)\end{array}$ & $\begin{array}{l}\text { Mid fit } \\
(n=17)\end{array}$ & $\begin{array}{l}\text { High fit } \\
(n=17)\end{array}$ & $P$ value \\
\hline \multicolumn{6}{|l|}{ Demographics } \\
\hline Male (\%) & 85 & 83 & 83 & 95 & - \\
\hline Age (years) & $72 \pm 5$ & $74 \pm 5$ & $69 \pm 4$ & $70 \pm 6$ & 0.801 \\
\hline Hypertensive (\%) & 33 & 30 & 30 & 35 & 0.913 \\
\hline \multicolumn{6}{|l|}{ Anthropometric measurements } \\
\hline Height (cm) & $174 \pm 8$ & $173 \pm 8$ & $172 \pm 7$ & $176 \pm 9$ & 0.223 \\
\hline Weight (kg) & $75 \pm 12$ & $75 \pm 12$ & $79 \pm 13$ & $76 \pm 10$ & 0.545 \\
\hline BMI $\left(\mathrm{kg} \cdot \mathrm{m}^{-2}\right)$ & $25 \pm 3$ & $25 \pm 3$ & $26 \pm 4$ & $25 \pm 3$ & 0.426 \\
\hline Body fat (\%) & $28 \pm 8$ & $27 \pm 8$ & $27 \pm 5$ & $22 \pm 5$ & 0.917 \\
\hline Waist:Hip ratio & $0.9 \pm 0.1$ & $1.0 \pm 0.1$ & $1.0 \pm 0.1$ & $0.9 \pm 0.1$ & 0.738 \\
\hline \multicolumn{6}{|c|}{ Resting heart rate and blood pressure } \\
\hline Heart rate (bpm) & $56 \pm 8$ & $59 \pm 8$ & $57 \pm 6$ & $51 \pm 6$ & 0.100 \\
\hline Brachial SBP (mmHg) & $131 \pm 18$ & $122 \pm 14$ & $124 \pm 10$ & $127 \pm 10$ & 0.471 \\
\hline Brachial DBP (mmHg) & $76 \pm 9$ & $72 \pm 9$ & $72 \pm 7$ & $73 \pm 6$ & 0.682 \\
\hline Central SBP (mmHg) & $115 \pm 6$ & $113 \pm 13$ & $114 \pm 9$ & $119 \pm 7$ & 0.185 \\
\hline Central DBP (mmHg) & $73 \pm 7$ & $73 \pm 9$ & $73 \pm 6$ & $74 \pm 6$ & 0.530 \\
\hline Central PP (mmHg) & $42 \pm 8$ & $40 \pm 7$ & $42 \pm 7$ & $46 \pm 9$ & 0.162 \\
\hline \multicolumn{6}{|l|}{ Medication use } \\
\hline ARB / ACE inhibitors (\%) & 22 & 12 & 6 & 24 & 0.314 \\
\hline Antiplatelets (\%) & 9 & 18 & 6 & 6 & 0.412 \\
\hline Beta-blockers (\%) & 4 & 12 & 0 & 0 & 0.125 \\
\hline Calcium channel blockers (\%) & 10 & 6 & 12 & 6 & 0.762 \\
\hline Statins (\%) & 27 & 30 & 35 & 18 & 0.662 \\
\hline \multicolumn{6}{|l|}{ Maximal incremental cycling test } \\
\hline $\mathrm{VO}_{2}$ peak $\left(\mathrm{L} \cdot \mathrm{min}^{-1}\right)$ & $2.2 \pm 0.6$ & $1.7 \pm 0.3$ & $2.2 \pm 0.4$ & $2.8 \pm 5.6$ & 0.001 \\
\hline$V_{2}$ peak $\left(m L \cdot k^{-1} \cdot m^{-1}\right)$ & $28.9 \pm 7$ & $22.3 \pm 3$ & $27.5 \pm 2$ & $36.3 \pm 6$ & 0.001 \\
\hline Peak heart rate (bpm) & $151 \pm 15$ & $142 \pm 15$ & $157 \pm 14$ & $156 \pm 10$ & 0.010 \\
\hline Peak RER (AU) & $1.17 \pm 0.1$ & $1.23 \pm 0.1$ & $1.13 \pm 0.1$ & $1.14 \pm 0.09$ & 0.020 \\
\hline Peak Power (Watts) & $163 \pm 40$ & $130 \pm 27$ & $160 \pm 27$ & $198 \pm 34$ & 0.001 \\
\hline
\end{tabular}

Data are presented as mean \pm SD or frequency (\%). $\mathrm{P}<0.05$ indicates significant difference between fitness groups. Heart rate and blood pressure data are an average of the resting measures collected on the three experimental visits. SBP, systolic pressure; DBP, diastolic pressure; cPP, central pulse pressure; BMI, body mass index; ARB, Angiotensin II receptor blockers; ACE, angiotensin converting enzyme; VO2, oxygen uptake; RER, respiratory exchange ratio. 
Table 2. Arterial stiffness at baseline and after control, moderate continuous- and high-intensity interval exercise in low-, mid- and high-fit groups

\begin{tabular}{|c|c|c|c|c|c|c|c|c|c|c|c|c|}
\hline & \multirow{2}{*}{$\begin{array}{l}\text { Fitness } \\
\text { groups }\end{array}$} & \multirow{2}{*}{ Protocol } & \multicolumn{6}{|c|}{ Time point (min) } & \multicolumn{4}{|c|}{$P$ values } \\
\hline & & & Baseline & 0 post & 20 post & 40 post & 60 post & 90 post & Time & Protocol & Group & Interactions \\
\hline \multirow{9}{*}{ PWV $\left(\mathbf{m} . \mathrm{s}^{-1}\right)$} & \multirow{3}{*}{ Low } & $\mathrm{CON}$ & $11.1 \pm 2.2$ & $12.0 \pm 2.1^{*}$ & $12.2 \pm 2.5^{*}$ & $12.2 \pm 2.0^{*}$ & $12.6 \pm 2.3^{*}$ & $12.7 \pm 2.0^{*}$ & \multirow{9}{*}{0.001} & \multirow{9}{*}{0.014} & \multirow{9}{*}{0.799} & \multirow{3}{*}{$\begin{array}{l}\text { Protocol*Time: } \\
0.009\end{array}$} \\
\hline & & MOD & $11.5 \pm 2.0$ & $12.1 \pm 2.2$ & $11.9 \pm 2.0$ & $12.2 \pm 2.4$ & $12.0 \pm 2.0$ & $12.9 \pm 2.2^{*}$ & & & & \\
\hline & & HIGH & $12.3 \pm 2.3$ & $12.1 \pm 2.5$ & $11.9 \pm 2.1$ & $12.3 \pm 1.9$ & $12.5 \pm 1.9$ & $13.1 \pm 2.3^{*}$ & & & & \\
\hline & \multirow{3}{*}{ Mid } & $\mathrm{CON}$ & $11.2 \pm 2.0$ & $11.9 \pm 2.0^{*}$ & $12.0 \pm 2.3^{*}$ & $12.0 \pm 2.0^{*}$ & $12.3 \pm 2.2^{*}$ & $12.4 \pm 2.2 *$ & & & & \\
\hline & & MOD & $11.3 \pm 2.1$ & $12.0 \pm 2.0$ & $11.7 \pm 2.0$ & $11.7 \pm 2.0$ & $11.8 \pm 2.1$ & $12.2 \pm 2.0^{*}$ & & & & \multirow{5}{*}{$\begin{array}{l}\text { Protocol*Group*Time: } \\
0.948\end{array}$} \\
\hline & & HIGH & $11.4 \pm 1.9$ & $11.9 \pm 1.8$ & $11.7 \pm 2.1$ & $11.6 \pm 2.1$ & $11.6 \pm 1.9$ & $12.3 \pm 2.0^{*}$ & & & & \\
\hline & \multirow{3}{*}{ High } & $\mathrm{CON}$ & $11.2 \pm 1.4$ & $12.0 \pm 1.9^{*}$ & $11.6 \pm 1.8^{*}$ & $11.8 \pm 1.8^{*}$ & $11.9 \pm 1.9 *$ & $12.4 \pm 1.9^{*}$ & & & & \\
\hline & & MOD & $11.3 \pm 1.9$ & $11.7 \pm 1.8$ & $11.3 \pm 1.6$ & $11.3 \pm 1.7$ & $11.5 \pm 1.9$ & $11.8 \pm 1.8^{*}$ & & & & \\
\hline & & HIGH & $11.3 \pm 2.0$ & $11.5 \pm 1.8$ & $11.5 \pm 1.9$ & $11.5 \pm 1.9$ & $11.5 \pm 1.9$ & $11.8 \pm 1.7^{*}$ & & & & \\
\hline \multirow{9}{*}{ Alx75 (\%) } & \multirow{3}{*}{ Low } & $\mathrm{CON}$ & $24.7 \pm 11$ & $22.6 \pm 9 *$ & $23.6 \pm 10^{*}$ & $21.5 \pm 12^{*}$ & $21.2 \pm 13 *$ & $24.0 \pm 10^{*}$ & \multirow{9}{*}{0.001} & \multirow{9}{*}{0.001} & & \multirow{4}{*}{$\begin{array}{l}\text { Protocol*Time: } \\
0.001\end{array}$} \\
\hline & & MOD & $26.5 \pm 11$ & $22.5 \pm 11$ & $28.0 \pm 13$ & $23.0 \pm 11^{*}$ & $22.5 \pm 13^{*}$ & $24.9 \pm 13 *$ & & & & \\
\hline & & HIGH & $24.9 \pm 11$ & $24.9 \pm 11$ & $24.9 \pm 11$ & $24.2 \pm 12^{*}$ & $23.0 \pm 13^{*}$ & $22.5 \pm 13 *$ & & & & \\
\hline & \multirow{4}{*}{ Mid } & $\mathrm{CON}$ & $23.8 \pm 9$ & $17.0 \pm 7^{*}$ & $18.2 \pm 6^{*}$ & $15.4 \pm 8^{*}$ & $16.0 \pm 8^{*}$ & $17.8 \pm 8^{*}$ & & & & \\
\hline & & MOD & $22.7 \pm 9$ & $21.5 \pm 9$ & $24.3 \pm 9$ & $19.0 \pm 8^{*}$ & $18.8 \pm 8^{*}$ & $19.5 \pm 8^{*}$ & & & 0.008 & \\
\hline & & HIGH & $25.0 \pm 9$ & $23.2 \pm 9$ & $25.0 \pm 8$ & $19.2 \pm 9^{*}$ & $18.8 \pm 10^{*}$ & $19.9 \pm 8^{*}$ & & & & \\
\hline & & $\mathrm{CON}$ & $14.7 \pm 10$ & $10.7 \pm 8^{*}$ & $13.4 \pm 10^{*}$ & $8.9 \pm 9^{*}$ & $10.0 \pm 9^{*}$ & $11.2 \pm 10^{*}$ & & & & Protocol* Group* Time: \\
\hline & High & MOD & $17.5 \pm 9$ & $15.5 \pm 8$ & $18.3 \pm 6$ & $13.1 \pm 6^{*}$ & $11.2 \pm 9^{*}$ & $14.6 \pm 7 *$ & & & & \\
\hline & & HIGH & $16.3 \pm 7$ & $17.8 \pm 8$ & $18.3 \pm 8$ & $14.7 \pm 9 *$ & $12.5 \pm 7 *$ & $13.3 \pm 7 *$ & & & & \\
\hline & & $\mathrm{CON}$ & $73.0 \pm 16$ & $77.7 \pm 12$ & $79.0 \pm 13$ & $78.9 \pm 13$ & $82.0 \pm 13$ & $79.4 \pm 12$ & & & & \\
\hline & Low & MOD & $80.4 \pm 13$ & $62.0 \pm 13^{*}$ & $74.9 \pm 10^{*}$ & $77.6 \pm 13$ & $77.9 \pm 14$ & $80.2 \pm 15$ & & & & Protocol*Time: \\
\hline & & HIGH & $82.7 \pm 13$ & $57.3 \pm 14^{*}$ & $79.7 \pm 15^{*}$ & $79.4 \pm 9 *$ & $76.5 \pm 12 *$ & $77.0 \pm 15^{*}$ & & & & 0.001 \\
\hline & & $\mathrm{CON}$ & $76.2 \pm 11$ & $71.7 \pm 10$ & $78.7 \pm 13$ & $77.2 \pm 12$ & $76.8 \pm 14$ & $77.2 \pm 13$ & & & & \\
\hline RM (\%) & Mid & MOD & $75.0 \pm 10$ & $63.2 \pm 11^{*}$ & $70.6 \pm 9 *$ & $72.8 \pm 10$ & $74.4 \pm 10$ & $71.9 \pm 13$ & 0.001 & 0.001 & 0.522 & \\
\hline & & HIGH & $78.0 \pm 9$ & $60.3 \pm 9 *$ & $69.3 \pm 12 *$ & $69.3 \pm 12^{*}$ & $70.9 \pm 12 *$ & $73.3 \pm 12 *$ & & & & \\
\hline & & $\mathrm{CON}$ & $78.5 \pm 13$ & $73.9 \pm 11$ & $74.3 \pm 10$ & $71.8 \pm 11$ & $73.3 \pm 13$ & $73.0 \pm 13$ & & & & Protocol" Group" I 1me: \\
\hline & High & MOD & $77.1 \pm 12$ & $70.7 \pm 11^{*}$ & $75.3 \pm 11^{*}$ & $78.0 \pm 11$ & $73.4 \pm 13$ & $74.9 \pm 9$ & & & & \\
\hline & & $\mathrm{HIGH}$ & $79.8 \pm 10$ & $65.0 \pm 12 *$ & $78.9 \pm 12 *$ & $75.1 \pm 10^{*}$ & $75.6 \pm 10^{*}$ & $73.0 \pm 13 *$ & & & & \\
\hline & & $\mathrm{CON}$ & $23.4 \pm 5.1$ & $24.6 \pm 5.8^{*}$ & $23.6 \pm 4.7$ & $22.5 \pm 5.0$ & $23.3 \pm 4.7$ & $25.0 \pm 4.7^{*}$ & & & & \\
\hline & Low & MOD & $23.6 \pm 6.2$ & $30.0 \pm 7.9^{*}$ & $24.8 \pm 6.3$ & $23.7 \pm 6.5$ & $23.9 \pm 5.9$ & $25.0 \pm 5.6$ & & & & Protocol*Time: \\
\hline & & HIGH & $22.1 \pm 4.6$ & $29.9 \pm 6.2^{*}$ & $24.4 \pm 5.8$ & $22.8 \pm 4.8$ & $23.8 \pm 4.8$ & $25.1 \pm 5.6^{*}$ & & & & 0.001 \\
\hline & & $\mathrm{CON}$ & $25.5 \pm 4.8$ & $26.1 \pm 6.0^{*}$ & $23.8 \pm 5.9$ & $24.5 \pm 6.5$ & $24.7 \pm 6.4$ & $25.1 \pm 6.4^{*}$ & & & & \\
\hline Pf (mmHg) & Mid & MOD & $24.3 \pm 4.4$ & $30.6 \pm 7.0^{*}$ & $25.2 \pm 5.6$ & $23.9 \pm 5.5$ & $24.8 \pm 6.4$ & $25.1 \pm 6.6$ & 0.001 & 0.241 & 0.090 & \\
\hline & & HIGH & $23.9 \pm 4.6$ & $30.4 \pm 7.0^{*}$ & $24.9 \pm 5.4$ & $24.2 \pm 6.0$ & $23.8 \pm 5.2$ & $25.4 \pm 7.5^{*}$ & & & & \\
\hline & & $\mathrm{CON}$ & $22.8 \pm 5.5$ & $25.1 \pm 4.8^{*}$ & $25.1 \pm 4.9$ & $24.5 \pm 4.7$ & $24.5 \pm 4.2$ & $25.8 \pm 6.1 *$ & & & & Trotocor "Uroup" IIme: \\
\hline & High & MOD & $24.3 \pm 5.1$ & $28.1 \pm 4.4^{*}$ & $24.5 \pm 5.5$ & $22.3 \pm 4.9$ & $22.9 \pm 4.8$ & $25.0 \pm 6.4$ & & & & \\
\hline & & HIGH & $23.8 \pm 5.0$ & $30.1 \pm 6.2^{*}$ & $22.9 \pm 4.6$ & $22.9 \pm 5.2$ & $22.2 \pm 4.4$ & $34.5 \pm 5.6^{*}$ & & & & \\
\hline & & $\mathrm{CON}$ & $16.7 \pm 3.1$ & $18.9 \pm 4.1^{*}$ & $18.6 \pm 4.6$ & $17.6 \pm 3.3$ & $19.0 \pm 4.2$ & $19.9 \pm 4.9^{*}$ & & & & \\
\hline & Low & MOD & $18.6 \pm 3.6$ & $18.2 \pm 3.2$ & $18.3 \pm 3.3^{*}$ & $18.1 \pm 3.5^{*}$ & $18.4 \pm 3.7$ & $20.0 \pm 5.0$ & & & & Protocol*Time: \\
\hline & & HIGH & $18.2 \pm 3.9$ & $16.8 \pm 3.0^{*}$ & $16.9 \pm 2.6^{*}$ & $17.4 \pm 3.3^{*}$ & $18.1 \pm 3.4^{*}$ & $19.1 \pm 4.1$ & & & & 0.046 \\
\hline & & $\mathrm{CON}$ & $19.4 \pm 3.3$ & $18.5 \pm 3.3^{*}$ & $18.4 \pm 3.5$ & $18.1 \pm 2.9$ & $18.6 \pm 3.5$ & $18.9 \pm 3.1^{*}$ & & & & \\
\hline Pb (mmHg) & Mid & MOD & $18.0 \pm 2.8$ & $19.2 \pm 4.2$ & $17.8 \pm 3.9^{*}$ & $17.2 \pm 3.4^{*}$ & $18.3 \pm 4.1$ & $17.7 \pm 3.4$ & 0.001 & 0.001 & 0.266 & \\
\hline & & HIGH & $18.5 \pm 2.4$ & $18.5 \pm 4.6^{*}$ & $17.1 \pm 3.1^{*}$ & $16.6 \pm 2.8^{*}$ & $16.7 \pm 3.1 *$ & $18.3 \pm 4.9$ & & & & \\
\hline & & $\mathrm{CON}$ & $17.8 \pm 4.1$ & $18.7 \pm 4.4^{*}$ & $18.8 \pm 4.2$ & $17.7 \pm 3.9$ & $18.0 \pm 3.9$ & $18.8 \pm 4.8^{*}$ & & & & 0909 \\
\hline & High & MOD & $18.7 \pm 4.2$ & $19.9 \pm 3.9$ & $18.2 \pm 3.2 *$ & $17.3 \pm 3.2^{*}$ & $16.6 \pm 3.2$ & $18.6 \pm 4.2$ & & & & \\
\hline & & HIGH & $19.0 \pm 3.8$ & $19.4 \pm 3.9^{*}$ & $18.0 \pm 3.9^{*}$ & $17.1 \pm 3.3^{*}$ & $16.8 \pm 3.4^{*}$ & $17.8 \pm 4.2$ & & & & \\
\hline
\end{tabular}

reflection magnitude; Pf, forward pressure wave; $\mathrm{Pb}$, backward pressure wave; $\mathrm{PWV}$, pulse wave velocity. *Significantly different to baseline based on protocol*time post-hoc comparisons. 
Table 3. Heart rate and central blood pressure indices at baseline and after control, moderate continuous- and high-intensity interval exercise in low, mid and high fit groups.

\begin{tabular}{|c|c|c|c|c|c|c|c|c|c|c|c|c|}
\hline & \multirow{2}{*}{$\begin{array}{l}\text { Fitness } \\
\text { groups }\end{array}$} & \multirow{2}{*}{ Protocol } & \multirow[b]{2}{*}{ Baseline } & \multirow[b]{2}{*}{0 post } & \multicolumn{3}{|c|}{ Time point (min) } & \multirow[b]{2}{*}{90 post } & \multicolumn{3}{|c|}{ P-Value } & \multirow[b]{2}{*}{ Interactions } \\
\hline & & & & & 20 post & 40 post & 60 post & & Time & Protocol & Group & \\
\hline \multirow{9}{*}{ HR (bpm) } & \multirow{3}{*}{ Low } & $\mathrm{CON}$ & $60 \pm 10$ & $56 \pm 9^{*}$ & $54 \pm 8^{*}$ & $54 \pm 8^{*}$ & $56 \pm 7^{*}$ & $55 \pm 8^{*}$ & \multirow{9}{*}{0.001} & \multirow{9}{*}{0.001} & \multirow{9}{*}{0.012} & \multirow{4}{*}{$\begin{array}{l}\text { Protocol*Time: } \\
0.001\end{array}$} \\
\hline & & MOD & $59 \pm 7$ & $67 \pm 9 *$ & $62 \pm 8^{*}$ & $59 \pm 7$ & $59 \pm 7$ & $59 \pm 7$ & & & & \\
\hline & & $\mathrm{HIGH}$ & $58 \pm 8$ & $71 \pm 12^{*}$ & $63 \pm 10^{*}$ & $61 \pm 9^{*}$ & $59 \pm 8$ & $58 \pm 7$ & & & & \\
\hline & \multirow{3}{*}{ Mid } & $\mathrm{CON}$ & $58 \pm 7$ & $54 \pm 6^{*}$ & $52 \pm 4^{*}$ & $51 \pm 4 *$ & $53 \pm 5^{*}$ & $53 \pm 3^{*}$ & & & & \\
\hline & & MOD & $56 \pm 6$ & $67 \pm 8^{*}$ & $62 \pm 7^{*}$ & $57 \pm 6$ & $57 \pm 5$ & $57 \pm 5$ & & & & \multirow{5}{*}{$\begin{array}{l}\text { Protocol*Group* Time: } \\
0.680\end{array}$} \\
\hline & & HIGH & $56 \pm 6$ & $67 \pm 8^{*}$ & $62 \pm 7^{*}$ & $57 \pm 6^{*}$ & $57 \pm 5$ & $57 \pm 5$ & & & & \\
\hline & \multirow{3}{*}{ High } & $\mathrm{CON}$ & $51 \pm 7$ & $46 \pm 5^{*}$ & $47 \pm 6^{*}$ & $46 \pm 6^{*}$ & $49 \pm 8^{*}$ & $48 \pm 6^{*}$ & & & & \\
\hline & & MOD & $52 \pm 6$ & $59 \pm 7 *$ & $55 \pm 8^{*}$ & $53 \pm 6$ & $52 \pm 5$ & $52 \pm 6$ & & & & \\
\hline & & HIGH & $51 \pm 6$ & $64 \pm 7 *$ & $59 \pm 7 *$ & $56 \pm 7 *$ & $53 \pm 6$ & $52 \pm 6$ & & & & \\
\hline \multirow{9}{*}{ cSBP (mmHg) } & \multirow{3}{*}{ Low } & $\mathrm{CON}$ & $111 \pm 14$ & $118 \pm 14^{*}$ & $116 \pm 14^{*}$ & $116 \pm 13^{*}$ & $117 \pm 14^{*}$ & $123 \pm 16^{*}$ & \multirow{9}{*}{0.001} & \multirow{9}{*}{0.001} & \multirow{9}{*}{0.727} & \multirow{4}{*}{$\begin{array}{l}\text { Protocol*Time: } \\
0.001\end{array}$} \\
\hline & & MOD & $115 \pm 15$ & $117 \pm 13 *$ & $112 \pm 13$ & $113 \pm 14 *$ & $115 \pm 12$ & $121 \pm 18^{*}$ & & & & \\
\hline & & HIGH & $114 \pm 13$ & $117 \pm 15^{*}$ & $102 \pm 12 *$ & $110 \pm 12^{*}$ & $114 \pm 12$ & $121 \pm 13^{*}$ & & & & \\
\hline & \multirow{4}{*}{ Mid } & $\mathrm{CON}$ & $118 \pm 9$ & $122 \pm 12 *$ & $120 \pm 12 *$ & $121 \pm 13^{*}$ & $121 \pm 13^{*}$ & $124 \pm 13^{*}$ & & & & \\
\hline & & MOD & $114 \pm 10$ & $121 \pm 11 *$ & $113 \pm 10$ & $113 \pm 10^{*}$ & $117 \pm 13$ & $120 \pm 15^{*}$ & & & & \\
\hline & & HIGH & $114 \pm 9$ & $118 \pm 12^{*}$ & $113 \pm 11^{*}$ & $113 \pm 13^{*}$ & $115 \pm 12$ & $122 \pm 15^{*}$ & & & & \\
\hline & & $\mathrm{CON}$ & $117 \pm 11$ & $122 \pm 11^{*}$ & $122 \pm 10^{*}$ & $120 \pm 9^{*}$ & $120 \pm 11 *$ & $125 \pm 15^{*}$ & & & & $\begin{array}{l}\text { Protocol"Group" I 1me: } \\
0805\end{array}$ \\
\hline & High & MOD & $119 \pm 11$ & $123 \pm 9^{*}$ & $116 \pm 8$ & $113 \pm 10^{*}$ & $114 \pm 11$ & $122 \pm 12^{*}$ & & & & \\
\hline & & HIGH & $117 \pm 9$ & $123 \pm 7^{*}$ & $113 \pm 8^{*}$ & $114 \pm 9 *$ & $114 \pm 10$ & $119 \pm 11^{*}$ & & & & \\
\hline & & $\mathrm{CON}$ & $72 \pm 8$ & $75 \pm 8^{*}$ & $73 \pm 9^{*}$ & $75 \pm 9^{*}$ & $75 \pm 8^{*}$ & $79 \pm 10^{*}$ & & & & \\
\hline & Low & MOD & $73 \pm 10$ & $75 \pm 9^{*}$ & $72 \pm 10$ & $72 \pm 10$ & $74 \pm 12$ & $78 \pm 12 *$ & & & & Protocol*Time: \\
\hline & & HIGH & $73 \pm 10$ & $77 \pm 12^{*}$ & $71 \pm 9$ & $72 \pm 9$ & $73 \pm 9$ & $76 \pm 10^{*}$ & & & & 0.048 \\
\hline & & $\mathrm{CON}$ & $74 \pm 7$ & $77 \pm 7^{*}$ & $76 \pm 7^{*}$ & $76 \pm 8^{*}$ & $78 \pm 8^{*}$ & $80 \pm 8^{*}$ & & & & \\
\hline cDBP (mmHg) & Mid & MOD & $72 \pm 6$ & $77 \pm 8^{*}$ & $73 \pm 7$ & $74 \pm 8$ & $75 \pm 9$ & $78 \pm 10^{*}$ & 0.001 & 0.007 & 0.904 & \\
\hline & & $\mathrm{HIGH}$ & $74 \pm 7$ & $76 \pm 7^{*}$ & $74 \pm 8$ & $74 \pm 9$ & $76 \pm 10$ & $79 \pm 9^{*}$ & & & & \\
\hline & & $\mathrm{CON}$ & $73 \pm 7$ & $74 \pm 7^{*}$ & $75 \pm 7^{*}$ & $74 \pm 7^{*}$ & $74 \pm 7^{*}$ & $78 \pm 9^{*}$ & & & & $\begin{array}{l}\text { Protocol*Group* Time: } \\
0.915\end{array}$ \\
\hline & High & MOD & $75 \pm 6$ & $77 \pm 7^{*}$ & $74 \pm 7$ & $73 \pm 7$ & $73 \pm 7$ & $77 \pm 9^{*}$ & & & & \\
\hline & & HIGH & $74 \pm 8$ & $78 \pm 8^{*}$ & $74 \pm 7$ & $75 \pm 9$ & $74 \pm 8$ & $75 \pm 8^{*}$ & & & & \\
\hline & & $\mathrm{CON}$ & $38 \pm 8$ & $44 \pm 6^{*}$ & $43 \pm 8^{*}$ & $41 \pm 4^{*}$ & $43 \pm 8^{*}$ & $45 . \pm 8^{*}$ & & & & \\
\hline & Low & MOD & $41 \pm 7$ & $42 \pm 7$ & $41 \pm 6$ & $41 \pm 6^{*}$ & $41 \pm 8$ & $44 \pm 8$ & & & & Protocol*Time: \\
\hline & & $\mathrm{HIGH}$ & $40 \pm 7$ & $40 \pm 6$ & $37 \pm 5^{*}$ & $38 \pm 5^{*}$ & $40 \pm 6^{*}$ & $45 \pm 7 *$ & & & & 0.001 \\
\hline & & $\mathrm{CON}$ & $44 \pm 9$ & $45 \pm 9^{*}$ & $44 \pm 8^{*}$ & $44 \pm 8^{*}$ & $44 \pm .9^{*}$ & $45 \pm 8^{*}$ & & & & \\
\hline cPP (mmHg) & Mid & MOD & $41 \pm 8$ & $44 \pm 9$ & $40 \pm 8$ & $40 \pm 9^{*}$ & $42 \pm 9$ & $42 \pm 9$ & 0.001 & 0.001 & 0.482 & \\
\hline & & HIGH & $41 \pm 6$ & $42 \pm 10$ & $39 \pm 7 *$ & $40 \pm 8^{*}$ & $39 \pm 7^{*}$ & $43 \pm 11^{*}$ & & & & \\
\hline & & $\mathrm{CON}$ & $44 \pm 10$ & $48 \pm 9^{*}$ & $47 \pm 9^{*}$ & $46 \pm 8^{*}$ & $46 \pm 6^{*}$ & $47 \pm 11 *$ & & & & $\begin{array}{l}\text { Protocol'Group* Iime: } \\
0.519\end{array}$ \\
\hline & High & MOD & $45 \pm 9$ & $46 \pm 8$ & $43 \pm 7$ & $41 \pm 7^{*}$ & $41 \pm 7$ & $45 \pm 10$ & & & & \\
\hline & & HIGH & $45 \pm 9$ & $45 \pm 8$ & $41 \pm 8^{*}$ & $40 \pm 7^{*}$ & $40 \pm 9^{*}$ & $44 \pm 10^{*}$ & & & & \\
\hline
\end{tabular}

Data are presented as mean $\pm \mathrm{SD}$; CON, no-exercise control; MOD, moderate-intensity exercise; HIGH, higher-intensity exercise; SBP systolic blood pressure; SDP, diastolic blood pressure; cPP, central pulse pressure. *Significantly different to baseline based on protocol*time post-hoc comparisons. 


\section{Figures}
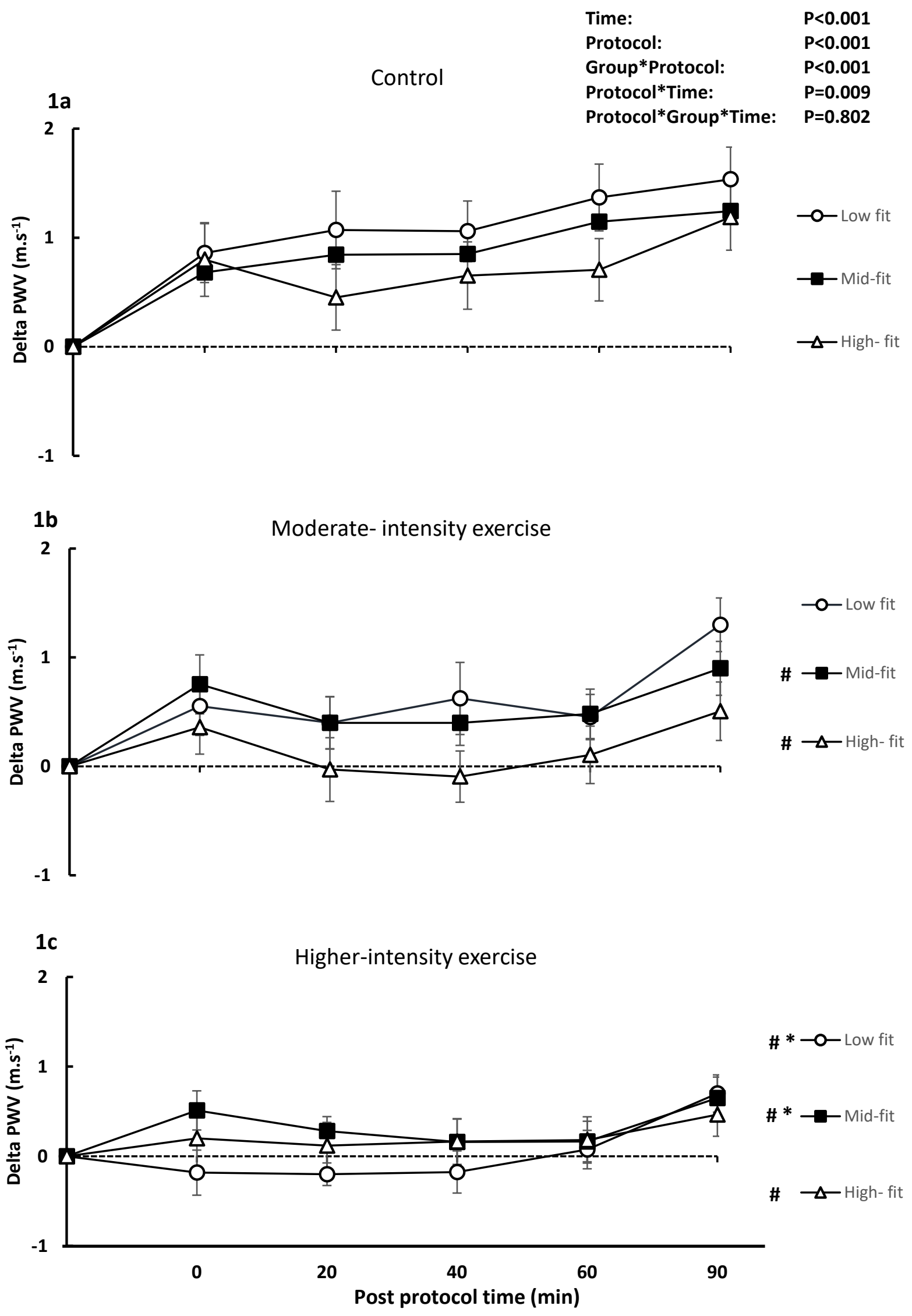
Fig. 1 Delta PWV response to control (a), moderate continuous (b) and higher-intensity interval (c). Delta PWV response between low-fit (circles), mid-fit (squares) and high-fit (triangles). Symbols and error bars represent mean \pm SEM; PWV, pulse wave velocity. \#significantly different to control; *high-intensity protocol significantly different to moderate-intensity protocol. 

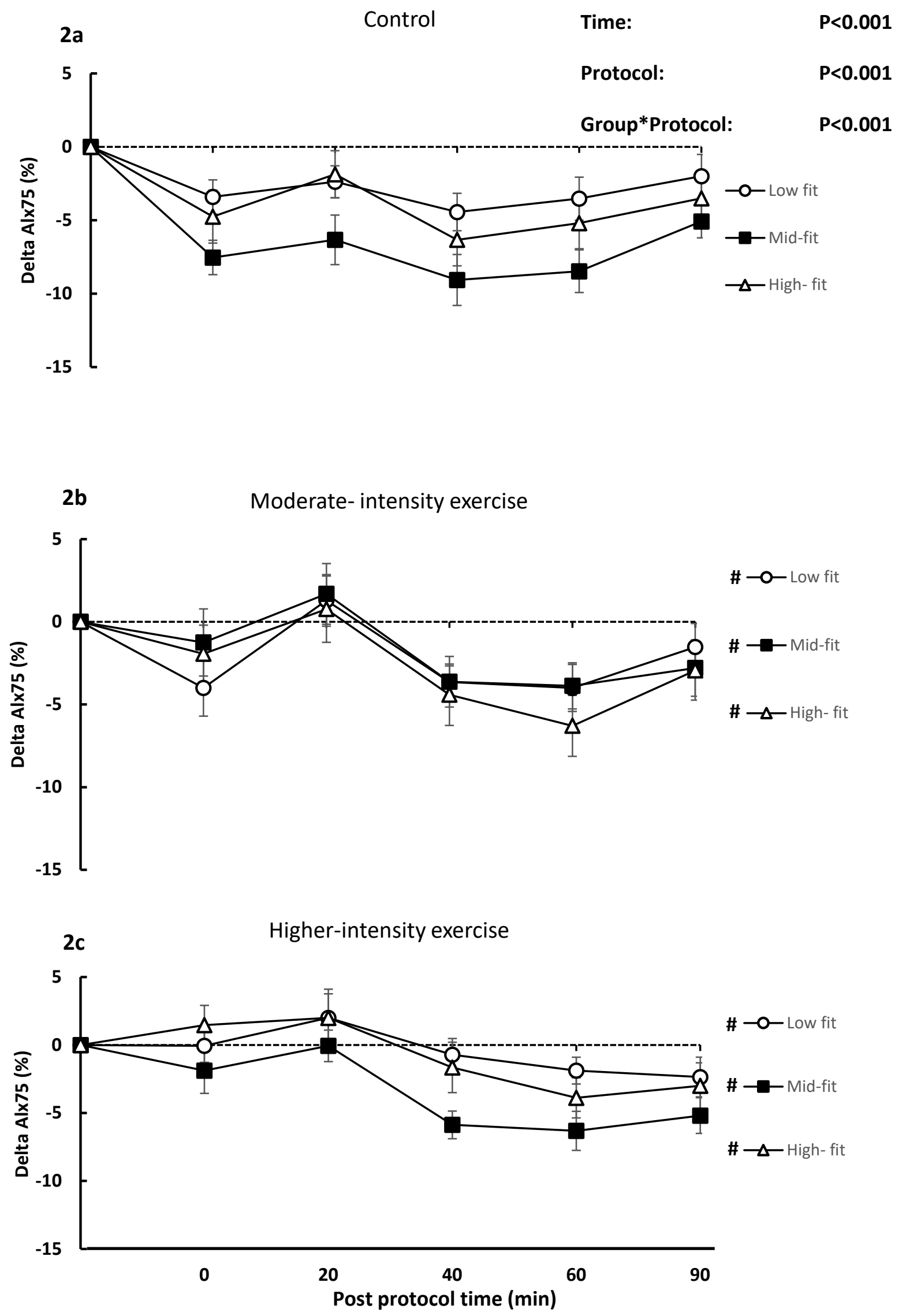
Fig. 2 Delta Alx75 response to control (a), moderate continuous (b) and higher-intensity interval (c). Delta Alx75 response between low-fit (circles), mid-fit (squares) and high-fit (triangles). Symbols and error bars represent mean $\pm \mathrm{SEM}$; AIx75, augmentation indexer normalised to a heart rate of $75 \mathrm{bpm}$. \#significantly different to control. 
Time:

$P<0.001$

Protocol:

$P<0.001$

3a

Control
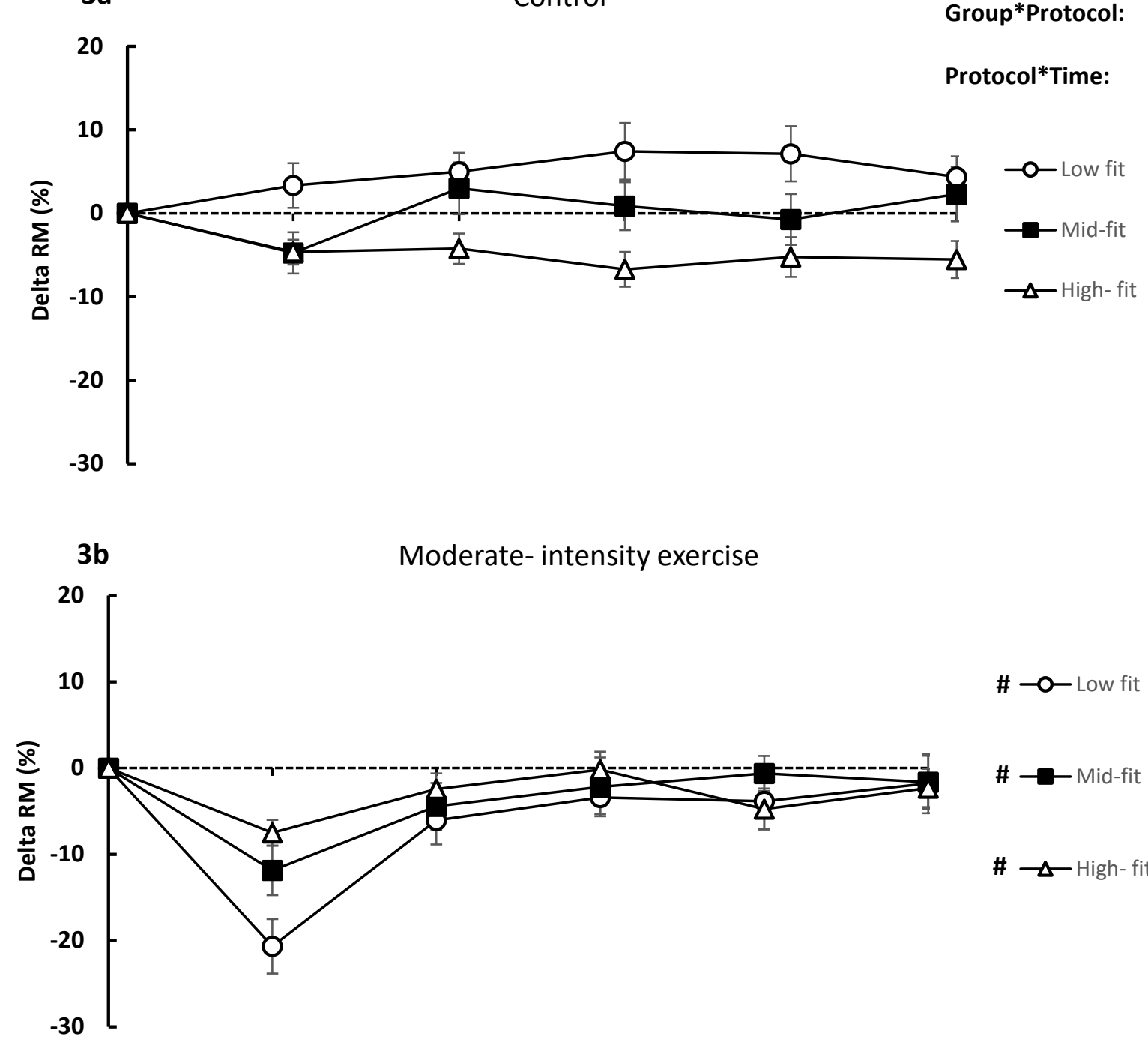

\#-0- Low fit

\#- Mid-fit

$\#-\Delta-$ High- fit

Higher-intensity exercise

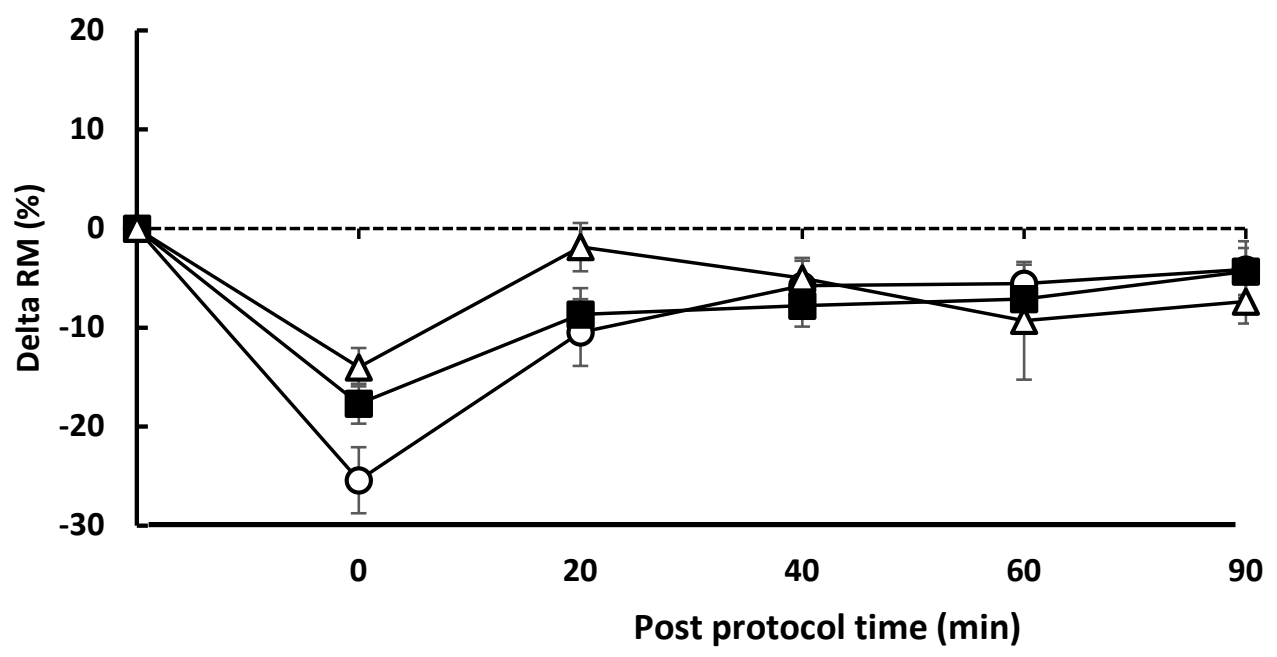

\# * - - Low fit

\# $*-$ Mid-fit

$\# \quad-\Delta$ High- fit 
Fig. 3 Delta RM response to control (a), moderate continuous (b) and higher-intensity interval (c). Delta RM response between low-fit (circles), mid-fit (squares) and high-fit (triangles). Symbols and error bars represent mean $\pm \mathrm{SEM}$; RM, reflection magnitude. \#significantly different to control; *high-intensity protocol significantly different to moderate-intensity protocol. 